\title{
One-Pot Synthesis of Cycloparaphenylenes
}

\author{
Jan H. Griwatz ${ }^{\text {a,b }}$ (i) \\ Hermann A. Wegner ${ }^{a, b *}$ (D) \\ ${ }^{a}$ Institute of Organic Chemistry, Justus Liebig University Giessen, Heinrich-Buff-Ring \\ 17, 35392, Giessen, Germany \\ ${ }^{b}$ Center for Materials Research, Justus Liebig University Giessen, Heinrich-Buff-Ring 16, \\ 35392, Giessen, Germany \\ Hermann.A.Wegner@org.chemie.uni-giessen.de
}

Received: 31.08.2020

Accepted after revision: 29.09.2020

DOI: 10.1055/s-0040-1721082; Art ID: om-20-0029oa

\section{License terms: (C)}

(c) 2020. The Author(s). This is an open access article published by Thieme under the terms of the Creative Commons Attribution-NonDerivative-NonCommercial-License, permitting copying and reproduction so long as the original work is given appropriate credit. Contents may not be used for commercial purposes, or adapted, remixed, transformed or built upon. (https://creativecommons.org/licenses/by-nc-nd/4.0/)

Abstract The preparation of cycloparaphenylenes ([n]CPPs) with their bent $\pi$-system poses a long-standing challenge in organic synthesis. In the current multi-step approaches to access CPPs, pre-angulated precursors were combined using transition metal-catalysed or mediated coupling reactions. Therefore, there is a long way to the realisation of the idea of an 'ideal synthesis'. An easy and efficient synthesis of different [n]CPPs would represent a breakthrough, also pushing their incorporation into organic materials. By combining multiple steps in a one-pot approach, the overall time and workload can be drastically shortened. Herein, we present the application of this concept for the preparation of [6] and [9]CPP as a simple and fast alternative to current methods. By tuning the reaction conditions the selective synthesis of both [6] and [9]CPP was demonstrated.

Key words cycloparaphenylenes, nanorings, organic synthesis, transition metal-free, carbon allotropes, macrocyclisation

\section{Introduction}

The preparation of complex structures, starting from sustainable materials, in $100 \%$ yield - the 'ideal synthesis' - is every chemist's dream. ${ }^{1}$ The concept is mostly discussed in the context of natural products' synthesis. However, there are also highly elaborate compounds beyond natural resources, which in no regards rank behind total syntheses of natural products in terms of number of steps, complexity and synthetic challenges. One example in this respect is the class of $[n]$ cycloparaphenylenes ( $[n] \mathrm{CPPs}$ ). These nanohoops consist of para-connected benzene rings in a cyclic arrangement resulting in considerable strain due to the bending of the phenyl units. CPPs represent the conceivably shortest segment of an armchair carbon nanotube. ${ }^{2,3}$ Early

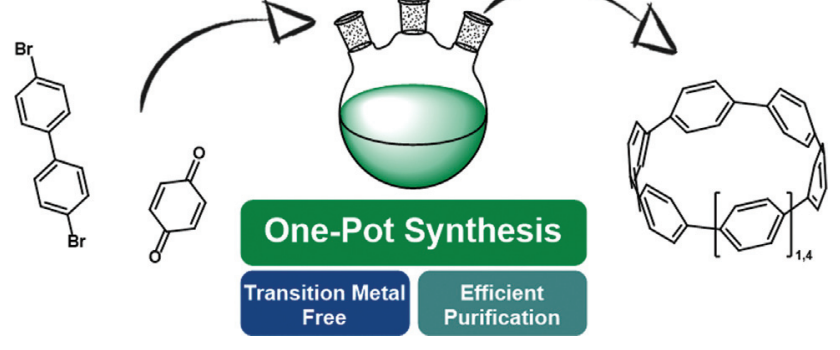

on, the unique geometry of CPPs has attracted the creativity of organic chemists. Already in the 1980s, Vögtle proposed a synthetic strategy using pre-angled building blocks, however, without being able to succeed in its achievement. ${ }^{4}$ It lasted until 2008, when Jasti and Bertozzi realized Vögtle's concept in the first synthesis of [9], [12] and [18]CPP (Scheme 1). ${ }^{2}$ Their approach relies on a statistical palladium-catalysed Suzuki macrocyclisation followed by reductive aromatisation using lithium naphthalenide. In the following years, several syntheses based on similar methodologies were reported. ${ }^{5,6}$ Itami's strategy relying on a cyclohexanedione moiety as angular building blocks offers a selective access to a variety of different-sized CPPs. ${ }^{7,8}$ However, it suffers from harsh oxidative aromatisation conditions, which are only practicable on smaller scales. ${ }^{7}$ The group of Yamago reported a different approach for the first time in $20100^{9,10}$ They made use of the formation of a stoichiometric Pt-complex to access an unstrained squareshaped macrocycle ultimately leading to a CPP in only four steps. Another approach based on stoichiometric transition metal complexes was reported by Osakada and co-workers. By using a gold complex, they obtained [6]CPP in good yields. ${ }^{11}$ Various strategies were reported in the due course to obtain also substituted CPPs using $[2+2+2]^{12}$ or DielsAlder cycloadditions. ${ }^{13}$ All approaches are limited to specific substitution patterns, though.

The necessity to access CPPs in a convenient and efficient way was recognised early on. Hence, some of these syntheses have been optimised to a large scale. However, most of the drawbacks of the initial attempts could not be overcome. Yamago's large-scale syntheses of $[5],{ }^{14}[6],{ }^{15}[8]^{16}$ and [10]CPP ${ }^{17}$ offer high overall yields, but are still based on stoichiometric amounts of transition metals (Scheme 1). The modular gram-scale synthesis of [8] and [10]CPP by Jasti and co-workers requires multiple steps including protection and deprotection. These time-consuming steps increase the total synthesis duration to almost 2 weeks. ${ }^{6}$

All preparations of CPPs mentioned in this article do not even remotely touch the idea of an 'ideal synthesis', ${ }^{1}$ in terms of number of steps, the need for protection groups or the utilisation of large amounts of expensive reagents or 


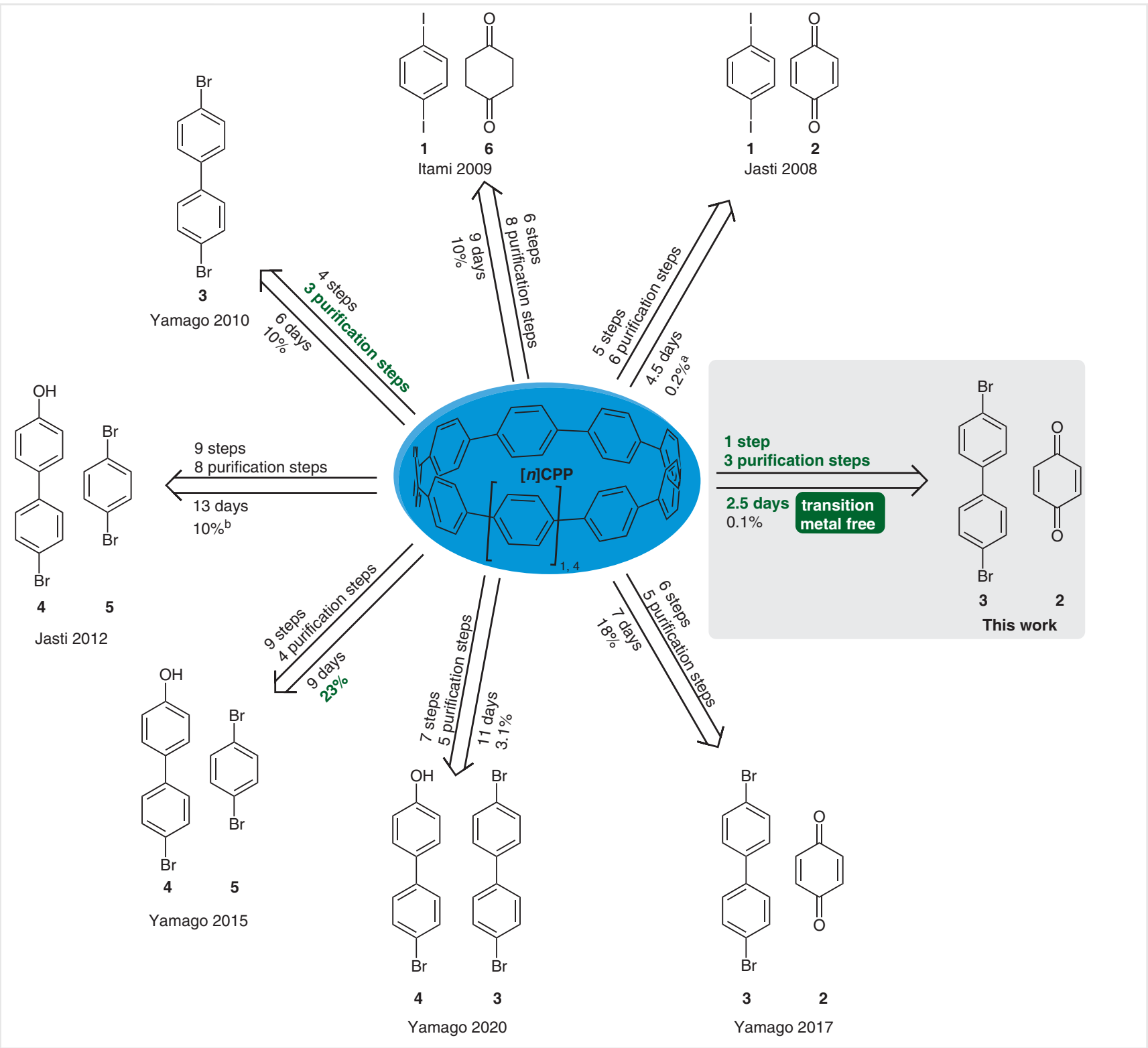

Scheme 1 Comparison of different CPP syntheses by the groups of Jasti, ${ }^{2,6}{ }^{\text {Itami }}{ }^{7}$ and Yamago, ${ }^{9,15-17}$ and the one-pot synthesis. ${ }^{\mathrm{a} O n l y}$ [9]CPP. ${ }^{\mathrm{b}}$ Only [8]CPP.

starting materials. The combination of multiple steps in a one-pot procedure would offer the possibility to drastically shorten the overall time and workload. The design of such a one-pot synthesis bears the challenge to ensure the compatibility of all reagents and intermediates. The application of the concept to CPPs has to combine firstly the formation of a less strained macrocyclic precursor and secondly the difficult aromatisation. Starting from cheap starting materials $(<0.2 \$ / g)^{18}$ in combination with an easy and non-labour-intensive purification, we herein report a fast and simple method to access different-sized CPPs. Furthermore, our method is the first example of a transition metal-free synthesis of CPPs.

\section{Results and Discussion}

The consecutive addition of a biphenyl building block to benzoquinone analogous to Yamago's gram-scale synthesis should provide the first intermediate. ${ }^{17}$ If this precursor is lithiated again at the terminal positions, a successive addition to another quinone will be possible (Scheme 2). However, here multiple problems arise: the double addition to benzoquinone could occur from either the same or different sides leading to the syn- or the anti-adduct. If the addition happens only once in the undesired anti-fashion, it will inevitably end up with oligomers or polymers. The ratio of syn-and anti-attack is reported to be around 95:5 and the 


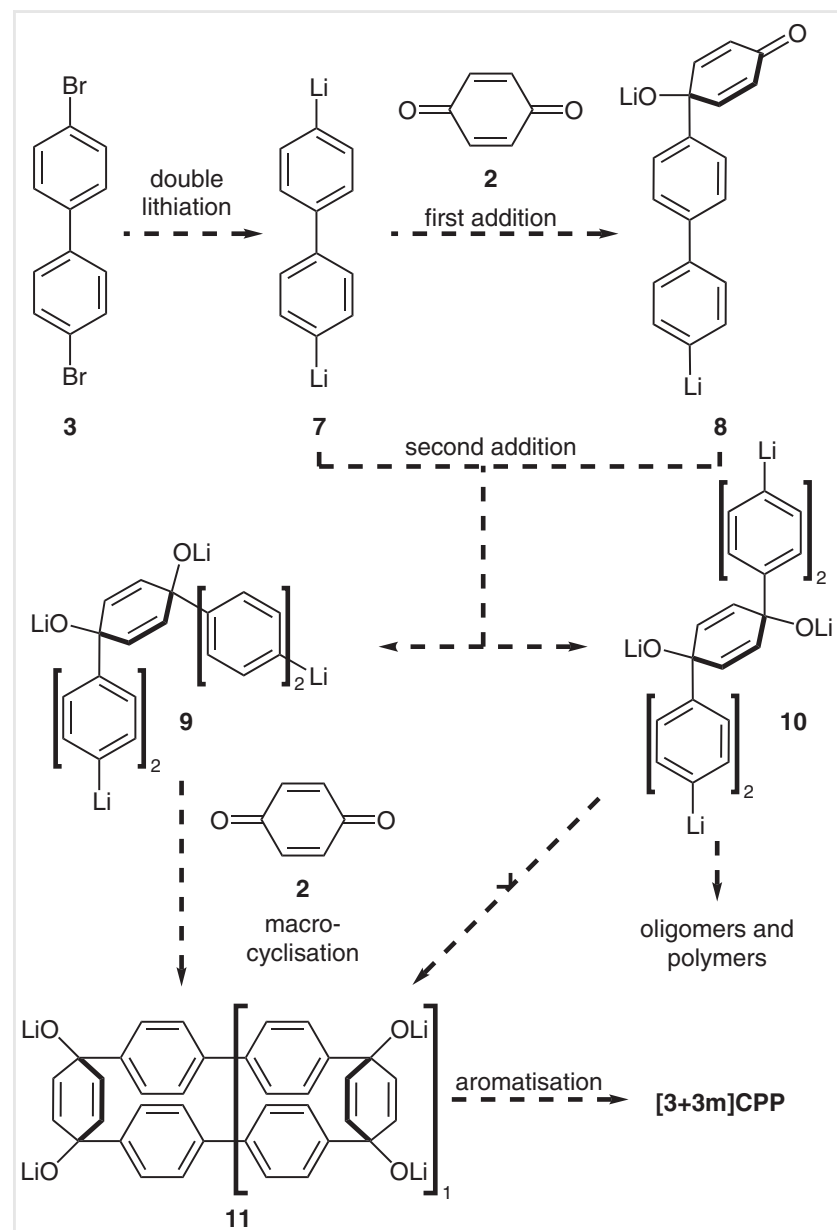

Scheme 2 Synthetic strategy towards a one-pot CPP synthesis. yield of the double addition is about $77 \% .{ }^{17,19,20}$ Another pitfall is the intramolecular macrocyclisation, which is entropically inherently disfavoured. Even if all steps are proceeded according to plan, the final aromatisation has to work without interaction with previously used reagents or intermediates. In spite of all these challenges, we initiated the development of a one-pot synthesis of CPPs, as a success would be of high value.

In the first attempt, biphenyl $\mathbf{3}$ was dilithiated by 2 equivalents of $n$-butyllithium ( $n$-BuLi) at $-78^{\circ} \mathrm{C}$ similarly to the procedure reported by Yamago (Table 1, entry 1$).{ }^{14}$ To this slurry, a solution of benzoquinone $\mathbf{2}$ was added. The mixture was warmed up to $-40{ }^{\circ} \mathrm{C}$ over $30 \mathrm{~min}$. To ensure a complete conversion of the arylhalide, the excess of $n$-BuLi was increased further and 1 equivalent of quinone 2 was added. The reaction mixture was quenched with an aqueous solution of tin(II) chloride dihydrate and hydrochloric acid to aromatise the proposed macrocyclic intermediate. After extraction with dichloromethane and purification by column chromatography, crude [9]CPP was obtained. After performing gel permeation chromatography (GPC) using chloroform as the eluent, gratefully [9]CPP was obtained in $0.1 \%$ yield $(5.1 \mathrm{mg})$. This is the first example of a transition metal-free CPP synthesis. As expected, the synthesis provided a large amount of side products and the column chromatography was complex. Therefore, we established a fast and selective separation technique to isolate the pure CPP (Figure 1). The crude reaction mixture was extracted with dichloromethane and adsorbed onto silica gel. The resulting solid was purified via Soxhlet extraction. Firstly, $n$ pentane was used to elute some of the side-products. No CPP was washed out under this condition [controlled by thin layer chromatography (TLC)]. Secondly, the solvent was switched to toluene continuing the Soxhlet extraction. The

Table 1 Overview of the different optimisation conditions

\begin{tabular}{|c|c|c|c|c|c|c|}
\hline & \multirow[t]{2}{*}{$c^{\mathrm{a}}(\mathrm{mol} / \mathrm{L})$ and Solvent } & \multirow[t]{2}{*}{ Addition of $2^{b}$} & \multirow[t]{2}{*}{ Temperature ${ }^{c}$} & \multirow[t]{2}{*}{ Time $^{d}$} & \multicolumn{2}{|c|}{ Yield } \\
\hline & & & & & [6]CPP & {$[9] \mathrm{CPP}$} \\
\hline 1 & $3 \times 10^{-2} \mathrm{THF}$ & $2 \times 1.00$ equiv & $-78^{\circ} \mathrm{C}$ & $2 \mathrm{~h}$ & - & $0.1 \%$ \\
\hline 2 & $7 \times 10^{-2} \mathrm{THF}$ & $4 \times 0.25$ equiv & $-40^{\circ} \mathrm{C}$ & $5 \mathrm{~h}^{\mathrm{e}}$ & traces & $0.01 \%$ \\
\hline 3 & $2 \times 10^{-2} \mathrm{THF}$ & 1.00 equiv & $-78^{\circ} \mathrm{C}$ & $20 \mathrm{~h}$ & - & $0.03 \%$ \\
\hline 4 & $2 \times 10^{-2} \mathrm{THF}$ & 1.00 equiv & $50{ }^{\circ} \mathrm{C}$ & $4 \mathrm{~h}$ & $0.07 \%$ & $0.05 \%$ \\
\hline 5 & $2 \times 10^{-2} \mathrm{THF}$ & $2 \times 0.50$ equiv $^{f}$ & $50^{\circ} \mathrm{C}$ & $4 \mathrm{~h}$ & - & $0.03 \%$ \\
\hline 6 & $2 \times 10^{-2} \mathrm{THF}$ & 1.00 equiv $^{f}$ & $50^{\circ} \mathrm{C}$ & $4 \mathrm{~h}$ & - & - \\
\hline 7 & $2 \times 10^{-2} 1,4$-dioxane & 1.00 equiv & $50^{\circ} \mathrm{C}$ & $4 \mathrm{~h}$ & traces & traces \\
\hline 8 & $2 \times 10^{-2} \mathrm{THF} / \mathrm{TMEDA}$ & 1.00 equiv & $50^{\circ} \mathrm{C}$ & $4 \mathrm{~h}$ & - & - \\
\hline 9 & $2 \times 10^{-2} \mathrm{THF} /$ benzene & 1.00 equiv & $50^{\circ} \mathrm{C}$ & $4 \mathrm{~h}$ & $0.04 \%$ & traces \\
\hline \multicolumn{7}{|c|}{ 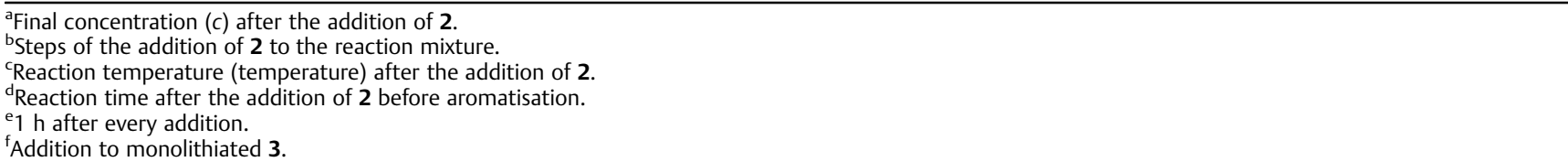 } \\
\hline
\end{tabular}




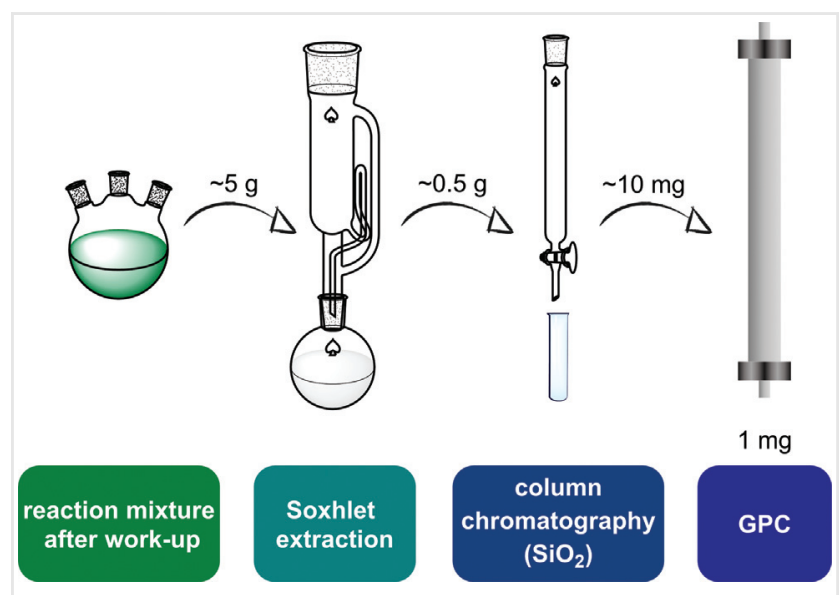

Figure 1 Purification work-flow.

crude CPP was completely extracted (TLC control). By this, the total amount of material was reduced by roughly $90 \%$ by weight and column chromatography became feasible.

After this encouraging result and an efficient purification method in hand, the one-pot approach was further optimised (Table 1). In a first attempt, the addition of benzoquinone 2 was varied. Usage of an excess of the lithiated species led to a higher conversion rate as reported by the groups of Jasti and Yamago. ${ }^{17,19}$ Benzoquinone was added successively to monolithiated dibromobiphenyl, which increased the relative concentration of biphenyl favouring the double addition (Table 1, entry 2).

After adding one additional equivalent of $n$-BuLi, the remaining quinone $\mathbf{2}$ was added in three portions to the reaction mixture. The reaction mixture was quenched as mentioned before. The Soxhlet extract (see description above) was further purified by column chromatography, providing a mixture of [6]CPP and [9]CPP. Finally, [9]CPP was isolated in a yield of $0.01 \%$ and [6]CPP in traces $(<<0.5 \mathrm{mg})$ after purification using GPC. Next, the reaction time was altered (Table 1, entry 3). TLC analysis showed no more change after $18 \mathrm{~h}$. Due to stirring problems using magnetic stirrers, an overhead stirrer was introduced. Afterwards $\mathrm{H}_{2} \mathrm{SnCl}_{4}$ was added to aromatise the expected macrocyclic intermediate. The reaction mixture was purified by Soxhlet extraction as mentioned before and column chromatography. After GPC purification, [9]CPP was obtained in $0.03 \%$ isolated yield. The yield was higher than that in the successive approach, but lower compared to the first synthesis. In order to increase the reactivity even more, the reaction mixture of the dilithiated biphenyl 7 and quinone 2 was heated to $50{ }^{\circ} \mathrm{C}$ immediately after the addition of 2 and stirred for $4 \mathrm{~h}$ (Table 1, Scheme 3 ). The reaction mixture was again purified by Soxhlet extraction and column chromatography. [9]CPP was obtained in $0.05 \%$ (1.2 mg) and [6]CPP in 0.07\% (1.7 mg) isolated yield after GPC.

To further investigate the formation of the corresponding macrocycles, stepwise lithiation of biphenyl $\mathbf{3}$ was performed (Table 1, entries 5 and 6). First, double addition

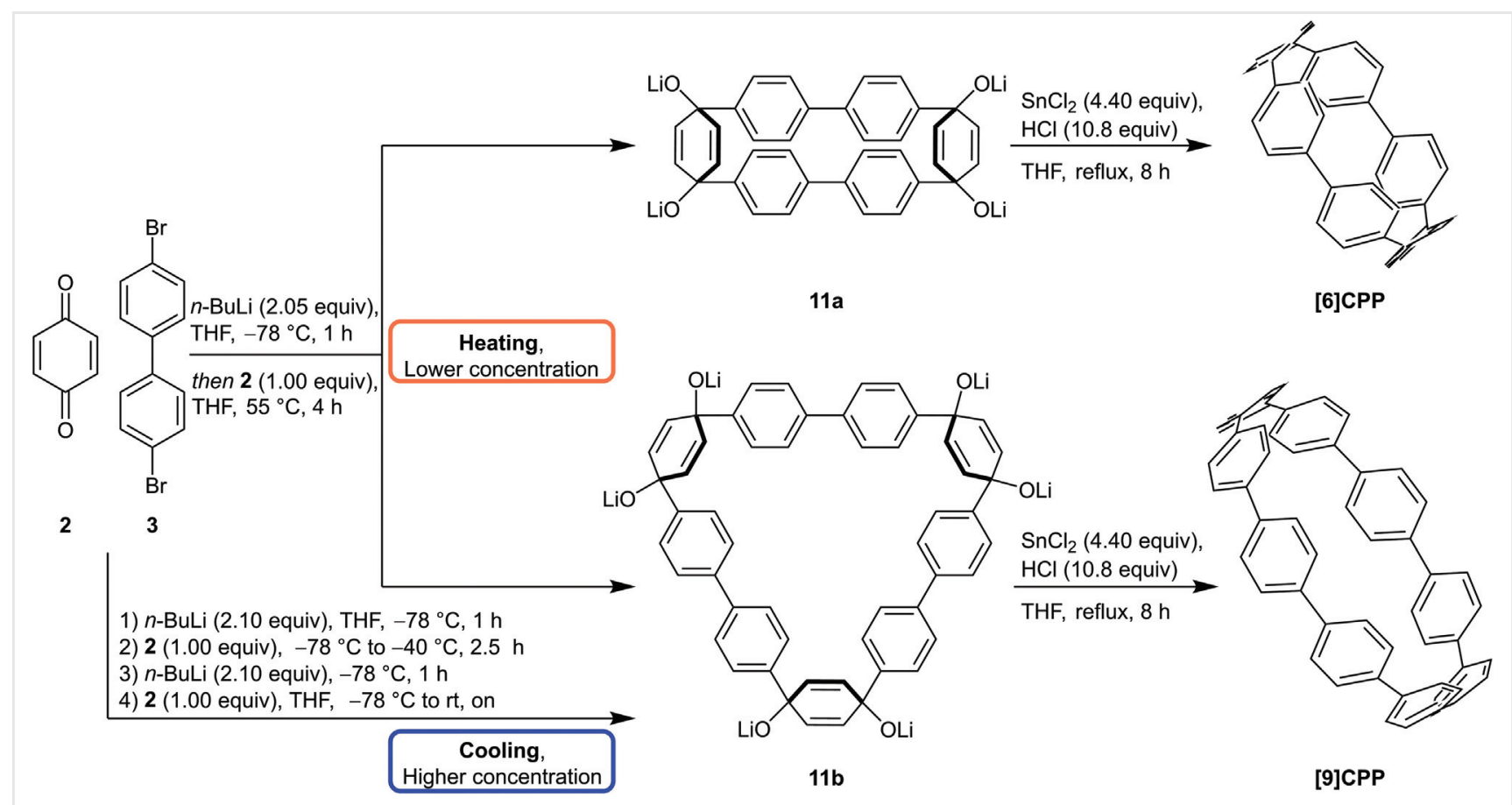

Scheme 3 Reaction scheme of the one-pot formation of [6] and [9]CPP and their corresponding macrocyclic precursors. 
of monolithiated biphenyl $\mathbf{3}$ to quinone $\mathbf{2}$ was tested. In theory, this would lead to a 5-membered precursor, which then could react to macrocycles by further lithiation and addition of $\mathbf{2}$. Using the same procedure as mentioned before, only [9]CPP was obtained in $0.03 \%(0.7 \mathrm{mg})$ isolated yield. Moreover, 1:1 addition of monolithiated biphenyl 3 to quinone $\mathbf{2}$ was performed. After further lithiation, followed by the standard procedure of aromatisation, no CPP was obtained (TLC control).

Next, different solvents were screened. Following the highest yielding procedure (Table 1 , entry 4 ), the solvents 1,4-dioxane, THF/TMEDA (9:1) and THF/benzene (1:1) were tested. In the case of 1,4-dioxane the addition of $n$-BuLi was carried out at room temperature (rt). The use of 1,4-dioxane and TMEDA as a (co-)solvent did not lead to the isolation of CPPs. However, the mixture of THF/benzene (1:1) led to the isolation of [6]CPP in $0.04 \%$ yield $(0.9 \mathrm{mg})$ as well as [9]CPP in traces.

By adding $p$-benzoquinone (2) successively to the reaction mixture, the yield dropped dramatically compared to the first approach. Nevertheless, this reaction yielded the highly strained [6]CPP under these one-pot conditions. Moreover, subsequent lithiation of biphenyl $\mathbf{3}$ (entries 5 and 6 ) combined with different addition sequences of $\mathbf{2}$ did not give higher yields. This could be explained by the stepwise lithiation and it has been reported that the lithiation of the double addition product to benzoquinone leads to decomposition. ${ }^{2}$ Also elongating the reaction time at a low temperature $\left(-78^{\circ} \mathrm{C}\right)$ did not increase the initial yield of the first approach (Table 1 , entry 3 ). The longer reaction time and lower temperature could favour linear adducts or rearrangements to less strained meta-connected side-products. ${ }^{21}$

The highest total isolated yield was observed when heating the reaction mixture to $50{ }^{\circ} \mathrm{C}$ in THF for $4 \mathrm{~h}$ in this study (Table 1, entry 4). Furthermore, [6]CPP was the main product, which led to the hypothesis that heating increases the total yield and also favours the formation of more strained cyclic precursor 11a (Scheme 3). In comparison to the first approach, the concentration was lowered in this case to favour intra- over intermolecular reactions. By reducing the concentration in combination with a higher reaction temperature, the one-pot synthesis showed a preference for the smaller [6]CPP (Scheme 3). Furthermore, the formation of [6]CPP was also favoured using THF/benzene as the solvent. This could lower the total reactivity of all lithiated species and favour intramolecular reactions.

\section{Conclusions}

In summary, we describe a transition metal-free onepot synthesis of [6] and [9]CPP. This is the fastest and easiest way to access cycloparaphenylenes reported so far. By developing a convenient purification work-flow, the targeted CPPs could be easily separated from the complex reaction mixtures. Starting from cheap materials, it opens up new ways and strategies for CPP synthesis.

\section{Experimental Section}

All reactions were carried out under inert conditions. Dry solvents were purchased from Acros Organics and stored under a nitrogen atmosphere. Technical grade solvents for column chromatography and extraction were distilled once prior to use. All reagents were purchased at reagent grade from commercial suppliers and were used without further purification. For column chromatography, silica gel $60(0.04-0.063 \mathrm{~mm})$ from Macherey-Nagel GmbH \& Co. was used. For TLC, SIL G/UV254 with $0.2-\mathrm{mm} \quad \mathrm{SiO}_{2}$-layer thickness from Macherey-Nagel GmbH \& Co. was used. Spots were detected with a UV-lamp at the wavelength of $254 \mathrm{~nm}$ or $366 \mathrm{~nm}$. Proton-nuclear magnetic resonance $\left({ }^{1} \mathrm{H}\right.$ NMR) spectra were measured on a Bruker Avance 400 (400 MHz) or a Bruker Avance 600 (600 MHz) spectrometer. Carbonnuclear magnetic resonance $\left({ }^{13} \mathrm{C}\right.$ NMR) spectra were measured on a Bruker Avance $400(101 \mathrm{MHz})$ or a Bruker Avance $600(151 \mathrm{MHz})$ spectrometer. All measurements were performed at rt. For GPC, a Shimadzu instrument (consisting of an LC-20AD pump unit, an SPD-20A detector unit (D2 lamp) and a CTO-20AC column oven) equipped with a PSS SDV preparative column (100 A, $300 \mathrm{~mm}$ length, $20.0 \mathrm{~mm}$ diameter) was used. As eluent 'Chloroform for HPLC stabilised with amylene' by Acros Organics (charge number: 268320025) was used.

\section{Procedures}

Selective synthesis of [9]CPP (Table 1, entry 1): Dibromobiphenyl 3 (6.37 g, $20.0 \mathrm{mmol}, 1.00$ equiv) was dissolved in dry THF (500 mL). The solution was cooled to $-78{ }^{\circ} \mathrm{C}$. A solution of $n$-BuLi (1.6 м in hexanes, $26.3 \mathrm{~mL}, 2.1$ equiv) was added slowly. The resulting light-green coloured suspension was stirred for $60 \mathrm{~min}$ at $-78{ }^{\circ} \mathrm{C}$. Then, p-benzoquinone (2) (2.16 g, $20 \mathrm{mmol}, 1.00$ equiv) was dissolved in dry THF (100 mL, in a second flask) and cooled to $-78^{\circ} \mathrm{C}$. The solution of quinone 2 was transferred to the first flask via a cannula and the solution was stirred for $2 \mathrm{~h}$ at $-78{ }^{\circ} \mathrm{C}$, then allowed to warm to $-40{ }^{\circ} \mathrm{C}$ for $30 \mathrm{~min}$ and again cooled to $-78{ }^{\circ} \mathrm{C}$. Again, a solution of $n$-BuLi (1.6 $\mathrm{m}$ in hexanes, $26.3 \mathrm{~mL}, 2.10$ equiv) was added slowly and stirring was continued for $60 \mathrm{~min}$ at $-78{ }^{\circ} \mathrm{C}$. Quinone 2 ( $2.16 \mathrm{~g}, 20 \mathrm{mmol}, 1.00$ equiv) was added as mentioned before, followed by stirring for $2 \mathrm{~h}$ at $-78{ }^{\circ} \mathrm{C}$. 
The mixture was allowed to warm to rt. Tin(II)chloride dihydrate (39.7 g, $176 \mathrm{mmol}, 8.80$ equiv) was dissolved in $\mathrm{HCl}$ (38\%, $35.0 \mathrm{~mL}, 434 \mathrm{mmol}, 21.7$ equiv) and stirred for $30 \mathrm{~min}$. The resulting solution was slowly added to the reaction mixture, which was heated under reflux for 1 day. The yellow-white solution was allowed to cool to rt. Water $(100 \mathrm{~mL})$ and $\mathrm{CH}_{2} \mathrm{Cl}_{2}(100 \mathrm{~mL})$ were added. The organic layer was separated and washed with water $(100 \mathrm{~mL})$ and brine $(100 \mathrm{~mL})$. The organic layer (very viscous) was dried with $\mathrm{MgSO}_{4}$, filtered off and washed with $\mathrm{CH}_{2} \mathrm{Cl}_{2}$ $(3 \times 200 \mathrm{~mL})$. The solvent was removed under reduced pressure and column chromatography was performed $\left(\mathrm{SiO}_{2}, 400 \mathrm{~g}\right.$, cyclohexane $\left./ \mathrm{CH}_{2} \mathrm{Cl}_{2}=1: 1\right)$. Fractions containing [9]CPP (green spot, $R_{\mathrm{f}}=0.45$ ) were combined and further purified by GPC $(6 \mathrm{~mL} / \mathrm{min}$, retention time $=12.29$ min). [9]CPP was obtained as a green solid (5.1 mg, 7.5 $\mu \mathrm{mol}, 0.1 \%$ ). The analytical data correspond to the literature data. ${ }^{2}$

Synthesis of [6] and [9]CPP (entry 4): Dibromobiphenyl 3 $(3.18 \mathrm{~g}, 10.0 \mathrm{mmol}, 1.00$ equiv) was dissolved in dry THF $(500 \mathrm{~mL})$. The solution was cooled to $-78^{\circ} \mathrm{C}$. A solution of $n$ BuLi (1.6 M, $12.8 \mathrm{~mL}, 20.5 \mathrm{mmol}, 2.05$ equiv) was added slowly and the resulting mixture was stirred (mechanical stirrer) for $1 \mathrm{~h}$ at $-78^{\circ} \mathrm{C}$. Quinone 2 (1.08 g, $10.0 \mathrm{mmol}, 1.00$ equiv) was added neat. The resulting solution was warmed up to $50^{\circ} \mathrm{C}$ and was stirred for $4 \mathrm{~h}$ at that temperature. Tin (II)chloride dihydrate (9.93 g, $44.0 \mathrm{mmol}, 4.40$ equiv) and $\mathrm{HCl}(38 \%, 8.72 \mathrm{~mL}, 108 \mathrm{mmol}, 10.8$ equiv) were mixed and slowly added to the reaction mixture followed by heating under reflux for $1.5 \mathrm{~h}$. The reaction was quenched by adding water $(100 \mathrm{~mL})$ and $\mathrm{CH}_{2} \mathrm{Cl}_{2}(200 \mathrm{~mL})$. The layers were separated, and the aqueous layer was washed with $\mathrm{CH}_{2} \mathrm{Cl}_{2}$ $(3 \times 100 \mathrm{~mL})$. The combined organic layers were washed with brine $(200 \mathrm{~mL})$ and dried with $\mathrm{MgSO}_{4}$ and concentrated under reduced pressure. The residue was taken up in $\mathrm{CH}_{2} \mathrm{Cl}_{2}$ and loaded onto silica gel $(20 \mathrm{~g})$. This solid was used for Soxhlet extraction with pentane $(10 \mathrm{~h})$, followed by toluene (4 h). TLC analysis showed a spot for [9]CPP (green, $R_{\mathrm{f}}=0.45$ ) only in the toluene extract. Column chromatography $\left(\mathrm{SiO}_{2}, 100 \mathrm{~g}\right.$, toluene/cyclohexane $\left.=1: 1\right)$ provided crude [9]CPP and [6]CPP. GPC was performed $(6 \mathrm{~mL} / \mathrm{min}$, retention time $=12.29$ and $13.57 \mathrm{~min}$ ) and pure [6]CPP (1.7 mg, $3.72 \mu \mathrm{mol}, 0.07 \%)$ and [9]CPP $(1.2 \mathrm{mg}, 1.75 \mu \mathrm{mol}$, $0.05 \%)$ were obtained. Analytical data correspond to the literature data. ${ }^{2,15}$

Please see Supporting Information for other entries (Table 1, entries 2, 3, and 5-9).

\section{Funding Information}

Financial support was provided by the Justus Liebig University Giessen.

\section{Acknowledgments}

We thank Domenic Dreisbach and Prof. Bernhard Spengler for MALDI-MS measurements. Furthermore, we thank Daniel Kohrs and Jannis Volkmann for fruitful discussions.

\section{Supporting Information}

Supporting information for this article is available online at http://doi.org/10.1055/s-0040-1721082.

\section{References}

(1) Wender, P. A. Nat. Prod. Rep. 2014, 31, 433.

(2) Jasti, R.; Bhattacharjee, J.; Neaton, J. B.; Bertozzi, C. R. J. Am. Chem. Soc. 2008, 130, 17646.

(3) Darzi, E. R.; Jasti, R. Chem. Soc. Rev. 2015, 44, 6401.

(4) (a) Vögtle, F. Topics in Current Chemistry, Vol. 115. Springer: Berlin, 1983. (b) Friederich, R.; Nieger, M.; Vögtle, F. Chem. Ber. 1993, 126, 1723.

(5) (a) Kayahara, E.; Patel, V. K.; Yamago, S. J. Am. Chem. Soc. 2014, 136, 2284. (b) Darzi, E. R.; Sisto, T. J.; Jasti, R. J. Org. Chem. 2012, 77, 6624. (c) Evans, P.; Zakharov, L. N.; Jasti, R. J. Photochem. Photobiol., A 2019, 382, 111878. (d) Evans, P. J.; Darzi, E. R.; Jasti, R. Nat. Chem. 2014, 6, 404. (e) White, B. M.; Zhao, Y.; Kawashima, T. E.; Branchaud, B. P.; Pluth, M. D.; Jasti, R. ACS Cent. Sci. 2018, 4, 1173. (f) Della Sala, P.; Talotta, C.; de Rosa, M.; Soriente, A.; Geremia, S.; Hickey, N.; Neri, P.; Gaeta, C. J. Org. Chem. 2019. (g) Xu, Y.; Wang, B.; Kaur, R.; Minameyer, M. B.; Bothe, M.; Drewello, T.; Guldi, D. M.; von Delius, M. Angew. Chem. Int. Ed. 2018, 57, 11549. (h) Van Raden, J. M.; Leonhardt, E. J.; Zakharov, L. N.; Pérez-Guardiola, A.; Pérez-Jiménez, A. J.; Marshall, C. R.; Brozek, C. K.; Sancho-García, J. C.; Jasti, R. J. Org. Chem. 2020, 85, 129.

(6) Xia, J.; Bacon, J. W.; Jasti, R. Chem. Sci. 2012, 3, 3018.

(7) Takaba, H.; Omachi, H.; Yamamoto, Y.; Bouffard, J.; Itami, K. Angew. Chem. Int. Ed. 2009, 48, 6112.

(8) (a) Segawa, Y.; Miyamoto, S.; Omachi, H.; Matsuura, S.; Šenel, P.; Sasamori, T.; Tokitoh, N.; Itami, K. Angew. Chem. Int. Ed. 2011, 50, 3244. (b) Segawa, Y.; Kuwabara, T.; Matsui, K.; Kawai, S.; Itami, K. Tetrahedron 2015, 71, 4500. (c) Omachi, H.; Segawa, Y.; Itami, K. Acc. Chem. Res. 2012, 45, 1378. (d) Omachi, H.; Matsuura, S.; Segawa, Y.; Itami, K. Angew. Chem. Int. Ed. 2010, 49, 10202.

(9) Yamago, S.; Watanabe, Y.; Iwamoto, T. Angew. Chem. Int. Ed. 2010, 49, 757.

(10) Iwamoto, T.; Watanabe, Y.; Sakamoto, Y.; Suzuki, T.; Yamago, S. J. Am. Chem. Soc. 2011, 133, 8354.

(11) Tsuchido, Y.; Abe, R.; Ide, T.; Osakada, K. Angew. Chem. Int. Ed. 2020. Doi: 10.1002/anie.202005482.

(12) (a) Tran-Van, A-F.; Huxol, E.; Basler, J. M.; Neuburger, M.; Adjizian, J-J.; Ewels, C. P.; Wegner, H. A. Org. Lett. 2014, 16, 1594. (b) Nishigaki, S.; Miyauchi, Y.; Noguchi, K.; Ito, H.; Itami, K.; Shibata, Y.; Tanaka, K. Eur.J. Org. Chem. 2016, 4668. (c) Nishigaki, S.; Shibata, Y.; Nakajima, A.; Okajima, H.; Masumoto, Y.; Osawa, T.; Muranaka, A.; Sugiyama, H.; Horikawa, A.; Uekusa, H.; Koshino, H.; Uchiyama, M.; Sakamoto, A.; Tanaka, K.J. Am. Chem. Soc. 2019, 141, 14955. 
(13) (a) Li, S.; Huang, C.; Thakellapalli, H.; Farajidizaji, B.; Popp, B. V.; Petersen, J. L.; Wang, K. K. Org. Lett. 2016, 18, 2268. (b) Farajidizaji, B.; Huang, C.; Thakellapalli, H.; Li, S.; Akhmedov, N. G.; Popp, B. V.; Petersen, J. L.; Wang, K. K. J. Org. Chem. 2017, 82, 4458. (c) Farajidizaji, B.; Thakellapalli, H.; Akhmedov, N. G.; Wang, K. K. J. Org. Chem. 2018, 83, 1216. (d) Huang, C.; Huang, Y.; Akhmedov, N. G.; Popp, B. V.; Petersen, J. L.; Wang, K. K. Org. Lett. 2014, 16, 2672.

(14) Patel, V. K.; Kayahara, E.; Yamago, S. Chemistry 2015 21, 5742.

(15) Kayahara, E.; Patel, V.; Xia, J.; Jasti, R.; Yamago, S. Synlett 2015, 26, 1615.
(16) Kawanishi, T.; Ishida, K.; Kayahara, E.; Yamago, S. J. Org. Chem. 2020, 85, 2082.

(17) Kayahara, E.; Sun, L.; Onishi, H.; Suzuki, K.; Fukushima, T.; Sawada, A.; Kaji, H.; Yamago, S. J. Am. Chem. Soc. 2017, 139, 18480.

(18) To evaluate the commercial availability and reagent costs, following suppliers were checked: Merck (Sigma Aldrich), TCI, Fisher Scientific (including Alfa Aesar).

(19) Sisto, T. J.; Golder, M. R.; Hirst, E. S.; Jasti, R. J. Am. Chem. Soc. 2011, 133, 15800.

(20) Schaub, T. A.; Margraf, J. T.; Zakharov, L.; Reuter, K.; Jasti, R. Angew. Chem. Int. Ed. 2018, 57, 16348.

(21) Golder, M. R.; Jasti, R. Acc. Chem. Res. 2015, 48, 557. 